\title{
TIVA vs. VIMA - BIS-guided anesthesia and hemodynamic stability in pediatric patients
}

Svraka D. ${ }^{1}$, Rakanovic D. ${ }^{1}$, Djurdjevic Svraka A. ${ }^{2}$, Golic D. ${ }^{1}$, Sobot Novakovic S. ${ }^{1}$, Tomic L. ${ }^{1}$

11. University Clinical Center of the Republic of Srpska, Dept of Anaesthesiology \& Intensive Care, Banjaluka, Bosnia and Herzegovina, ${ }^{2}$ General hospital Gradiska, Dept of Anaesthesiology \& Intensive Care, Gradiska, Bosnia and Herzegovina

Background and Goal of Study: Bispectral index was specifically developed to measure the hypnotic effects of anaesthesia and allows better titration of anesthesia, resulting in lower hypnotic drug use and improved recovery. The study compared hemodynamic stability $( \pm 20 \%$ from baseline mean arterial pressure - MAP) pediatric patients undergoing adenotonsillectomy using two standard anesthetic techniques - BIS -guided total intravenous anesthesia (TIVA) and inhalation anesthesia (VIMA).

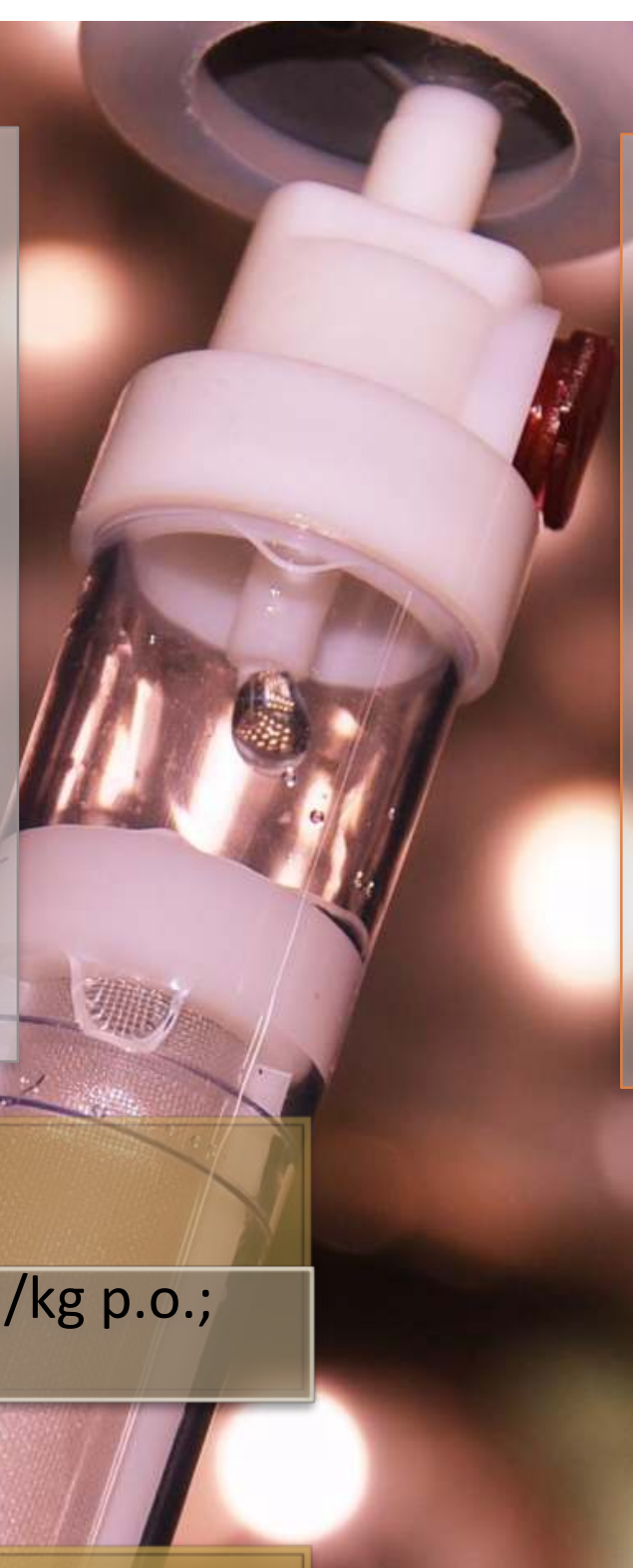

Induction of anaesthesia

TIVA: Propofol $2,5 \mathrm{mg} / \mathrm{kg}$, Remifentanil $1 \mu / \mathrm{kg}$, atracurium $0,5 \mathrm{mg} / \mathrm{kg}$ VIMA: O2 : N2 50:50\%; Sevofluran Vol.8..6..4..Atracurium 0,5 mg/kg

\section{.}
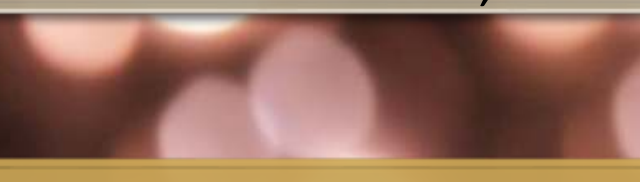

\section{Maintenance}

Propofol $100 \mu \mathrm{g} / \mathrm{kg} / \mathrm{min}$; ( $\pm 25 \%)$,Remifentanil 0,25 $\mu \mathrm{g} / \mathrm{kg} / \mathrm{min}$ O2:N2O 50:50; Sevofluran 2.5 vol\% ( $\pm 25 \%)$

\section{Results:}

The mean baseline MAP was $85.09 \mathrm{mmHg}(\mathrm{SD}=14.55)$ in TIVA and 84.61 $\mathrm{mmHg}(\mathrm{SD}=10.70)$ in VIMA group.

Mean MAP during anaesthesia maintenance was $81.64 \mathrm{mmHg}(\mathrm{SD}=9.40)$ in TIVA group and $77.73 \mathrm{mmHg}(\mathrm{SD}=7.07)$ in VIMA group.

The analysis of covariance (ANCOVA), there were statistically significant differences in MAP during anaesthesia maintenance between groups (taking into account the duration of the operation, as well as baseline MAP): $F(1,96)=$ $4.59, \mathrm{p}=.035, \mathrm{n} 2=.046$, but without clinical importance.

Hemodynamic instability ( $\pm 20 \%$ of initial blood pressure) is registered in 11 (22\%) patients in the TIVA group, and 10 (20\%) patients in the VIMA group. Using the chi-square test there was no statistically significant difference in the number of hemodynamically unstable patients: $\chi 2(1, N=100)=0.06, p=.81$, $\mathrm{w}=.02$.

\section{Conclusion:}

BIS guided TIVA or VIMA shows no statistically significant difference in hemodinamic instability during maintenance of anesthesia( $\pm 20 \%$ baseline). Although statistically significant differences in the values of MAP during maintenance of anesthesia was noted, the same have no clinical significance.

\section{Literature:}

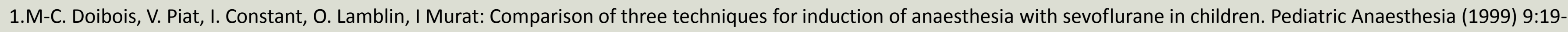
23

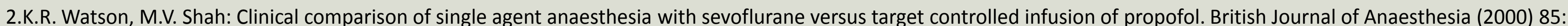
541-6

3.G. Schneider, C. Elidrissi, P.S Sebel: Bispectral index-guided administration of anaesthesia: comparison between remifentanil/propofol and remifentanil/isoflurane. European Journal of Anesthesiology (2003) 20: 624-630 